\title{
亚热带森林附生地衣压力-体积曲线分析及其适用性
}

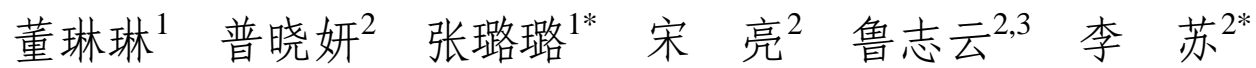 \\ ${ }^{1}$ 山东师范大学环境与生态研究院, 济南 250358; ${ }^{2}$ 中国科学院西双版纳热带植物园热带森林生态学重点实验室, 昆明 $650223 ;{ }^{3}$ 中国科学院哀牢山亚 \\ 热带森林生态系统研究站, 云南景东 676209
}

摘 要 附生地衣是森林生态系统中的重要组成部分, 在维护森林物种多样性以及水分和养分循环等方面发挥着重要作用。 地衣类群的水势特征以及压力-体积(PV)曲线及相关参数是否适用于探索地衣等变水性生物类群应对水分胁迫机制, 仍有待 阐明。该研究以中国西南地区云南哀牢山亚热带山地森林中 5 个类群 15 种常见附生地衣为对象, 探讨了其PV曲线及水势参数 的功能群和物种水平的变化。结果显示, 蓝藻型地衣的内部含水量 $\left(W C_{\text {internal }}\right)$ 和共质体水含量 $(R s)$ 显著高于绿藻型地衣, 是其 1 倍以上, 但其他参数表现出较高的一致性。功能群水平上, 地衣仅 $W C_{\mathrm{internal}} 、 R s$ 和膨压损失点的相对含水量 $\left(R W C_{\mathrm{TLP}}\right)$ 具有显著 性差异; 但物种间差异均非常显著。结合主成分分析进一步发现, PV曲线及相关参数在评估地衣整体应对水分胁迫以及揭示 生境水分条件选择策略时具有较大的限制性, 受到共生藻和生长型的显著影响; 但内部最大持水力可以解释蓝藻型地衣的生 境适应策略, 而部分参数如饱和渗透势 ( $\Psi \mathrm{sat}$ )和 $R W C_{\mathrm{TLP}}$ 可以分别用于解释狭叶地衣、阔叶地衣和枝状地衣对生境水分条件的 适应。研究表明PV曲线及水势参数不适用于地衣类群整体的抗旱性评价, 和其他生物类群进行抗旱性比较时更要慎用。

关键词 地衣; 水势参数; 内部含水量; 压力-体积曲线; 主成分分析; 变水植物

董琳琳, 普晓妍, 张璐璐, 宋亮, 鲁志云, 李苏 (2021). 亚热带森林附生地衣压力-体积曲线分析及其适用性. 植物生态学报, 45, 274-285. DOI: $10.17521 /$ cjpe.2020.0344

\section{Pressure-volume curve analysis of epiphytic lichens and its applicability in subtropical forests} DONG Lin-Lin ${ }^{1}$, PU Xiao-Yan ${ }^{2}$, ZHANG Lu-Lu ${ }^{1 *}$, SONG Liang ${ }^{2}$, LU Zhi-Yun ${ }^{2,3}$, and LI Su ${ }^{2 *}$

${ }^{1}$ Institute of Environment and Ecology, Shandong Normal University, Jinan 250358, China; ${ }^{2}$ CAS Key Laboratory of Tropical Forest Ecology, Xishuangbanna Tropical Botanical Garden, Chinese Academy of Sciences, Kunming 650223, China; and ${ }^{3}$ Ailaoshan Station for Subtropical Forest Ecosystem Studies, Chinese Academy of Sciences, Jingdong, Yunnan 676209, China

\section{Abstract}

Aims Epiphytic lichens are a widespread and significant component of forest ecosystems, and play an important role in biodiversity maintaining and water and nutrient cycling. This study aims to illustrate the water potential characteristics of the epiphytic lichen group and to assess whether the pressure-volume (PV) curve and relative parameters are suitable for exploring the response of lichens to drought stress.

Methods The water potential parameters and PV curves of 15 epiphytic lichen species from five functional groups were measured in the subtropical forests in the Ailao Mountains, Yunnan Province.

Important findings The internal water content $\left(W C_{\text {internal }}\right)$ and symplast water content $(R s)$ of cyanolichens were significantly higher than those of chlorolichens, while other parameters showed no significant differences. We only observed significant differences in $W C_{\text {internal }}, R s$ and relative water content at turgor loss point $\left(R W C_{\mathrm{TLP}}\right)$ among different functional groups of lichens. All parameters differed significantly among species. Results of principal component analysis (PCA) further indicated that there are extensive limitations for PV curves and water potential parameters in evaluating the overall response of lichen species to water stress and in revealing the selection strategy of water-related habitats, largely due to the influence of the photobiont type and growth form. However, the adaptation strategies of cyanolichens to habitat could be explained by the maximum internal water holding capacity, while the adaptation to water conditions could be explained by the saturated water osmotic potential ( $\Psi$ sat) in narrowly lobed foliose lichens, and by the $R W C_{\mathrm{TLP}}$ in broadly lobed foliose and fruticose

收稿日期Received: 2020-10-20 接受日期Accepted: 2021-01-02

基金项目: 国家自然科学基金(31770494和3175001)、中国科学院青年创新促进会项目(2017441)、中国科学院“西部之光”项目和中国科学院135项目 (2017XTBG-T01)。Supported by the National Natural Science Foundation of China (31770494 and 3175001), the Youth Innovation Promotion Association of the Chinese Academy of Sciences (CAS)(2017441), CAS “Light of West China” Program, and the CAS 135 Program (2017XTBG-T01).

* 通信作者Corresponding author (Li S: lis@xtbg.ac.cn; Zhang LL: 675359138@qq.com) 
lichens. Our study suggests that PV curves and water potential parameters are not suitable for the general evaluation of the drought resistance of lichen communities, and should be used carefully in comparing the drought resistances between lichens and other plant groups.

Key words epiphytic lichen; water potential; internal water content; pressure-volume curve; principal component analysis; poikilohydric plant

Dong LL, Pu XY, Zhang LL, Song L, Lu ZY, Li S (2021). Pressure-volume curve analysis of epiphytic lichens and its applicability in subtropical forests. Chinese Journal of Plant Ecology, 45, 274-285. DOI: 10.17521/cjpe.2020.0344

地衣是异养真菌和一种或多种自养藻类的共生 体, 共生藻(photobiont)为绿藻或包括蓝藻(蓝细菌), 分别称为绿藻型地衣 (chlorolichen) 和蓝藻型地衣 (cyanolichen)(Nash, 2008)。在森林生态系统中, 生活 于植物活体或残体上但不从宿主体内掠夺营养与水 分的地衣类群, 通常被称为附生地衣 (epiphytic lichen)(Barkman, 1958)。地衣类群大约占据了 $8 \%$ 的 陆地表面积, 在维护生态系统的物种多样性以及水 分和养分循环等方面发挥着重要作用(Nardini et al., 2013)。

地衣因其菌藻共生、无表皮层分化等生理和结 构特性, 缺少维管植物所具有的根系和外层蜡质表 皮及气孔等保护性结构, 虽然能够直接吸收其生长 基物表面或空气中的营养物质和水分, 但缺少水分 保持能力, 是典型的变水植物 (poikilohydric plant) (Lange, 2003)。尽管地衣对水分的利用没有明显的 自主调控能力, 但可以与外界环境快速交换水分, 因而得以在极端干燥状态下生存, 也能在重新湿润 后迅速恢复代谢活动(Smith \& Molesworth, 1973)。 因此, 地衣的生理活动极易受到环境水分条件的显 著影响。

压力-体积曲线(PV曲线)是使用最广泛的表征 植物水分状况最广泛使用的工具(Wenkert et al., 1978)。通过测量植物组织从完全饱和状态直至脱水 干燥以后失水全过程的水势 $(\Psi)$ 与相对含水量 $(R W C)$ 的变化, 绘制饱和叶片失水过程中叶水势的负倒数 $(-1 / \Psi)$ 和相对含水量 $(1-R W C)$ 之间关系的 $\mathrm{PV}$ 曲线, 获取和评估共质体含水量 $(R s)$ 、质外体含水量 $(R a)$ 、 膨压损失点的相对含水量 $\left(R W C_{\mathrm{TLP}}\right)$ 和渗透势 $\left(\Psi_{\mathrm{TLP}}\right)$ 、以及饱和渗透势 $(\Psi \mathrm{sat})$ 等参数 $($ 附录 $\mathrm{I})$ 。这些 参数综合体现了植物组织内部的水分状况及潜在忍 耐力, 是衡量植物应对环境干旱胁迫能力的重要指 标, 广泛应用于草本(Sato et al., 2006; Motalebifard et al., 2013), 灌木(Saruwatari \& Davis, 1989; 蔡静如 等, 2015), 乔木(Zheng et al., 2010; Yan et al., 2013;
张林森等, 2013)类群耐早性的评价。然而, 对于变 水生物如苔藓和地衣来说, PV曲线及相关参数是否 适用于其干旱胁迫响应的分析, 尚未得到广泛研究 和一致结论。少量研究证明, 部分地卷属(Peltigera) 地衣具有较低的 $\Psi$ sat和 $\Psi_{\mathrm{TLP}}$, 在干燥生境中具有明 显的生存优势(Nardini et al., 2013)。

迄今, 地衣类群的生态学研究仍缺乏足够关注, 而地衣应对干旱环境的详细机制更是亟待阐述。基 于此, 本研究选取云南哀牢山国家级自然保护区亚 热带森林系统中15种常见附生地衣物种为对象, 分 析其PV曲线及相关参数, 以期揭示附生地衣对环 境水分条件变化的响应, 同时衡量PV曲线及相关 参数是否适用于探索地衣应对干旱胁迫的机制, 为 阐明亚热带常绿阔叶林水分调控附生地衣空间分布 格局及内在生理学机制提供理论依据。

\section{1 材料和方法}

\section{1 研究区概况}

哀牢山位于云贵高原西南部、横断山区南段以 东, 属云岭山脉向南分支的余脉, 是全球生物多样 性保护热点Indo-Burma区域的一部分(Olson \& Dinerstein, 1998)。本研究位于哀牢山国家级自然保护区 核心区域景东徐家坝片区 $\left(23.35^{\circ}-24.44^{\circ} \mathrm{N}\right.$, $\left.100.53^{\circ}-101.30^{\circ} \mathrm{E}\right)$, 海拔约为2 400-2 $750 \mathrm{~m}$ 。该地 区降雨丰沛, 终年温凉潮湿, 年降水量约 $1947 \mathrm{~mm}$, 年蒸发量约1 $192 \mathrm{~mm}$, 相对湿度约为 $85 \%$; 月平均 最高气温为 $15.8{ }^{\circ} \mathrm{C}$, 月平均最低气温为 $4.5{ }^{\circ} \mathrm{C}$, 年平 均气温 $11.3{ }^{\circ} \mathrm{C}$ (李苏等, 2007 ; 朱华和间丽春, 2009)。中山湿性常绿阔叶林是哀牢山徐家坝地区的 主要原生森林植被, 林内附生生物种类繁多, 地衣 是附生类群的重要组成部分, 目前已记录 217 种 $(\mathrm{Li}$ et al., 2013a, 2013b)。

\section{2 研究材料}

结合 $\mathrm{Li}$ 等(2013a, 2013b)对本地区附生地衣物种 分布的研究, 本研究选择云南哀牢山中山湿性常绿 
阔叶林内15种常见附生地衣为研究对象(表1)。按照 共生藻和生活型差异, 将其划分为5个不同的功能 群(McCune, 1993; Nimis \& Martellos, 2008)。在每个 目标物种主要生境中采集其健康个体, 带回哀牢山 生态站实验室, 清洗干净, 晾干后放入含有硅胶的 密封袋中, 干燥保存备用。

\section{3 研究方法}

使用WP4C露点水势仪(Decagon Devices, Washington, USA)完成地衣水势测定。使用 $0.5 \mathrm{~mol} \cdot \mathrm{L}^{-1} \mathrm{KCl}$ 溶液对水势仪进行校准后, 参照Tyree和 Hammel (1972)的方法, 将地衣置于蒸馏水中浸没 $1 \mathrm{~h}$ 以上 至饱和, 取出地衣样品并剪取稍小于样品杯内径 (直径约 $3 \mathrm{~cm}$, 高度约 $1 \mathrm{~cm}$ ) 的片段, 以期尽可能覆
盖样品杯底部, 提高测量精度。擦干样品表面残留 水分, 称质量(记作 $B M$ ), 迅速将样品置于压力室 中, 平衡至读数稳定后, 记录水势 $(\Psi)$ 。然后将样 品静置于温度约 $15{ }^{\circ} \mathrm{C}$ 、光照约 $100 \mu \mathrm{mol} \cdot \mathrm{m}^{-2} \cdot \mathrm{s}^{-1}$ 的 恒定环境中，利用地衣变水特性使其自然脱水， 期间多次测定其鲜质量 $\left(m_{\mathrm{F}}\right)$ 和 $\Psi$, 重复上述过程直 至样品失水至质量基本不再减少。最后将样品置 于烘箱 $70{ }^{\circ} \mathrm{C} 48 \mathrm{~h}$, 称量干质量 $\left(m_{\mathrm{D}}\right)$ 。每个物种做 5 个重复。

\section{4 数据处理和分析}

首先, 地衣样品相对含水量 $(R W C, \%)$ 根据以下 公式计算:

$$
R W C=\left(m_{\mathrm{F}}-m_{\mathrm{D}}\right) /(B W-D W)
$$

表1 云南哀牢山亚热带森林目标附生地衣的生长特性

Table 1 Growth characteristics of target epiphytic lichens in subtropical forests in the Ailao Mountains, Yunnan

\begin{tabular}{|c|c|c|c|c|}
\hline 物种 Species & 共生藻型 Photobiont type & 生长型 Growth form & 功能群划分 Functional group & 主要生境 Main habitat \\
\hline $\begin{array}{l}\text { 网肺衣 } \\
\text { Lobaria retigera (Lobret) }\end{array}$ & 蓝藻 Cyanobacteria & 叶状 Foliose & $\begin{array}{l}\text { 蓝藻型地衣 } \\
\text { Cyanolichen (CYL) }\end{array}$ & $\begin{array}{l}\text { 阴湿至高光照湿润生境 } \\
\text { Shaded to high-light and } \\
\text { humid habitat }\end{array}$ \\
\hline $\begin{array}{l}\text { 猫耳衣 } \\
\text { Leptogium menziesii (Lepmen) }\end{array}$ & 蓝藻 Cyanobacteria & 叶状 Foliose & CYL & 潮湿环境 Humid habitat \\
\hline $\begin{array}{l}\text { 黑芽牛皮叶 } \\
\text { Sticta fuliginosa (Stiful) }\end{array}$ & 蓝藻 Cyanobacteria & 叶状 Foliose & CYL & $\begin{array}{l}\text { 潮湿高光照生境 } \\
\text { Humid and high-light habitat }\end{array}$ \\
\hline $\begin{array}{l}\text { 针芽肺衣 } \\
\text { Lobaria isidiophora (Lobisi) }\end{array}$ & 绿藻 Green alga & $\begin{array}{l}\text { 阔叶型 } \\
\text { Broadly lobed foliose }\end{array}$ & $\begin{array}{l}\text { 阔叶绿藻型地衣 } \\
\text { Broadly lobed foliose } \\
\text { chlorolichens (BFL) }\end{array}$ & $\begin{array}{l}\text { 中光至高光照生境 } \\
\text { Medium to high-light habitat }\end{array}$ \\
\hline $\begin{array}{l}\text { 网大叶梅 } \\
\text { Parmotrema reticulatum (Parret) }\end{array}$ & 绿藻 Green alga & $\begin{array}{l}\text { 阔叶型 } \\
\text { Broadly lobed foliose }\end{array}$ & BFL & $\begin{array}{l}\text { 中光至高光照、潮湿生境 } \\
\text { Medium to high-light, and } \\
\text { humid habitat }\end{array}$ \\
\hline $\begin{array}{l}\text { 平滑牛皮叶 } \\
\text { Sticta nylanderiana (Stinyl) }\end{array}$ & 绿藻 Green alga & $\begin{array}{l}\text { 阔叶型 } \\
\text { Broadly lobed foliose }\end{array}$ & BFL & $\begin{array}{l}\text { 中光至高光照生境 } \\
\text { Medium to high-light habitat }\end{array}$ \\
\hline $\begin{array}{l}\text { 黑腹绵腹衣 } \\
\text { Anzia hypomelaena (Anzhyp) }\end{array}$ & 绿藻 Green alga & $\begin{array}{l}\text { 狭叶型 } \\
\text { Narrowly lobed foliose }\end{array}$ & $\begin{array}{l}\text { 狭叶绿藻型地衣 } \\
\text { Narrowly lobed foliose } \\
\text { chlorolichens (NFL) }\end{array}$ & $\begin{array}{l}\text { 高光照生境 } \\
\text { High-light habitat }\end{array}$ \\
\hline $\begin{array}{l}\text { 短根条衣 } \\
\text { Everniastrum nepalense (Evenep) }\end{array}$ & 绿藻 Green alga & $\begin{array}{l}\text { 狭叶型 } \\
\text { Narrowly lobed foliose }\end{array}$ & NFL & $\begin{array}{l}\text { 高光照生境 } \\
\text { High-light habitat }\end{array}$ \\
\hline $\begin{array}{l}\text { 卷梢哑铃孢 } \\
\text { Heterodermia boryi (Hetbor) }\end{array}$ & 绿藻 Green alga & $\begin{array}{l}\text { 狭叶型 } \\
\text { Narrowly lobed foliose }\end{array}$ & NFL & $\begin{array}{l}\text { 高光照生境 } \\
\text { High-light habitat }\end{array}$ \\
\hline $\begin{array}{l}\text { 云南袋衣 } \\
\text { Hypogymnia yunnanensis (Hypyun) }\end{array}$ & 绿藻 Green alga & $\begin{array}{l}\text { 狭叶型 } \\
\text { Narrowly lobed foliose }\end{array}$ & NFL & $\begin{array}{l}\text { 高光照生境 } \\
\text { High-light habitat }\end{array}$ \\
\hline $\begin{array}{l}\text { 裂髓树花 } \\
\text { Ramalina conduplicans (Ramcon) }\end{array}$ & 绿藻 Green alga & $\begin{array}{l}\text { 直立枝状 } \\
\text { Shrubby fruticose }\end{array}$ & $\begin{array}{l}\text { 直立枝状绿藻型地衣 } \\
\text { Shrubby fruticose } \\
\text { chlorolichens (SFL) }\end{array}$ & $\begin{array}{l}\text { 高光照生境 } \\
\text { High-light habitat }\end{array}$ \\
\hline $\begin{array}{l}\text { 槽枝衣 } \\
\text { Sulcaria sulcata (Sulsul) }\end{array}$ & 绿藻 Green alga & $\begin{array}{l}\text { 直立枝状 } \\
\text { Shrubby fruticose }\end{array}$ & SFL & $\begin{array}{l}\text { 高光照生境 } \\
\text { High-light habitat }\end{array}$ \\
\hline $\begin{array}{l}\text { 多花松夢 } \\
\text { Usnea florida (Usnflo) }\end{array}$ & 绿藻 Green alga & $\begin{array}{l}\text { 直立枝状 } \\
\text { Shrubby fruticose }\end{array}$ & SFL & $\begin{array}{l}\text { 高光照生境 } \\
\text { High-light habitat }\end{array}$ \\
\hline $\begin{array}{l}\text { 巢松萝 } \\
\text { Usnea dasopoga (Usndas) }\end{array}$ & 绿藻 Green alga & $\begin{array}{l}\text { 悬垂枝状 } \\
\text { Pendent fruticose }\end{array}$ & $\begin{array}{l}\text { 悬垂枝状绿藻型地衣 } \\
\text { Pendent fruticose } \\
\text { chlorolichens (PFL) }\end{array}$ & $\begin{array}{l}\text { 高光照且干燥生境 } \\
\text { High-light and dry habitat }\end{array}$ \\
\hline $\begin{array}{l}\text { 长松萝 } \\
\text { Usnea longissima (Usnlon) }\end{array}$ & 绿藻 Green alga & $\begin{array}{l}\text { 悬垂枝状 } \\
\text { Pendent fruticose }\end{array}$ & PFL & $\begin{array}{l}\text { 高光照潮湿生境 } \\
\text { High-light and humid habitat }\end{array}$ \\
\hline
\end{tabular}

引自Li et al. (2013a)和Eriksson et al. (2018)。

Cited from Li et al. (2013a) and Eriksson et al. (2018).

www.plant-ecology.com 
其中 $M 、 B W$ 和 $D W$ 分别是指实测时、饱和时(水势为 0 时的叶片鲜质量)和烘干后的质量(Song et al., 2015)。

植物细胞失水初期, $\Psi$ 等于渗透势 $(\Psi 0)$ 与压力 势 $(\Psi \mathrm{p})$ 之和。膨压减少, 水势降低。 $(\Psi-\Psi \mathrm{p}) \times V$ 为 常量, 其中, $V$ 为渗透水含量。此时, $1 / \Psi$ 与 $V$ 呈双曲 线关系。植物组织因失水至质壁分离点时, $\Psi \mathrm{p}=0$, $\Psi$ 就只有 $\Psi 0$, 即 $\Psi \times V$ 为常量, $1 / \Psi$ 与 $V$ 呈线性关系 (李洪建等, 2004)。基于此, 以 $(1-R W C)$ 为横坐标、 $-1 / \Psi$ 为纵坐标作图, 绘制PV曲线, 并计算相关参数 (Beckett, 1997)。膨压损失点(TLP) 是PV曲线的快速 下降和线性下降部分的转折点(Tyree \& Hammel, 1972)。

通过双曲线回归拟合TLP上方的变化趋势为:

$$
-1 / \Psi=y 0+a \times b /(b+1-R W C)
$$

其中, $\Psi$ 是水势, $a 、 b$ 和 $y 0$ 是系数。

通过线性回归拟合TLP以下直线部分:

$-1 / \Psi=y 0+a \times(1-R W C)$

其中, $\Psi$ 是水势, $a$ 和 $y 0$ 是系数。

根据PV曲线, 方程(2)和(3)的交点表示地衣质 壁分离的临界状况, 该点横坐标对应临界含水量 $\left(1-R W C_{\mathrm{TLP}}, \%\right)$, 纵坐标对应临界水势的负倒数 $\left(-1 / \Psi_{\mathrm{TLP}},-\mathrm{MPa}\right)$ 。将方程(3)直线双向延长, 与横坐 标的交点为 $R s$ 和 $R a$ 分界点, $X$ 轴截距为 $1-R W C$, $R s=(B W-M) / D W ; R a=(M-D W) / D W$ 。二者转化为 相对于干质量的含水量即为绝对含水量, 且总和等 于地衣内部含水量 $\left(W C_{\text {internal, }}\right.$, Esseen et al., 2017)(同 时, $\left.W C_{\text {internal }}=(B W-D W) / D W \times 100 \%\right)$ 。直线与纵坐 标的交点为地衣 $\Psi$ sat 的负倒数(Tyree \& Hammel, 1972; Song et al., 2015)。

为比较共生藻型、生长型和物种之间地衣PV曲 线参数的变化, 利用SPSS 26, 首先对相关数据进行 正态性和方差齐性检验。如满足上述要求, 则利用 方差分析及Tukey's HSD多重比较进行分析; 若无 法满足相关检验, 则采取非参数Kruskal-Wallis秩和 检验和Wilcoxon秩和检验进行相应分析。

同时使用R语言软件(R Development Core Team, 2019)进行主成分分析(PCA)。PCA分析前, 根据参 数之间的相关性, 剔除高共线性因子 $(|r|>0.7)$ 其中 的1个, 保留更具有生态学意义和解释的因子。然后 将相关参数标准化, 提取主成分(遵循特征值大于 1 的原则), 以探讨附生地衣相关参数的适用性以及
主要的参数或梯度。

\section{2 结果}

\section{1 蓝藻型和绿藻型地衣PV曲线及其参数的比较}

PV曲线拟合结果显示(图1A、1B), 蓝藻型地衣 双曲线拟合 $\left(R_{\mathrm{adj} .}^{2}=0.35, p=0.59\right)$ 和直线回归拟合 $\left(R_{\text {adj. }}^{2}=0.75, p<0.0001\right.$ ) 均比绿藻型地衣 (双曲线拟 合 $R_{\text {adj. }}^{2}=0.18, p<0.0001$; 直线拟合 $R_{\text {adj. }}^{2}=0.50, p<$ 0.0001 ) 具有更高的拟合性, 但前者双曲线拟合并 不显著。

水势参数分析结果显示, 蓝藻型和绿藻型地衣 之间除 $W C_{\text {internal }}\left(\chi^{2}=25.735, p<0.001\right)$ 和 $R s\left(\chi^{2}=\right.$ 26.004, $p<0.001$ )差异极其显著外, 其他参数如 $R a$ $(F=0.893, p=0.348) 、 R W C_{\mathrm{TLP}}\left(\chi^{2}=1.343, p=\right.$ $0.246) 、 \Psi_{\text {TLP }}(F=0.589, p=0.445)$ 及 $\Psi$ sat $(F=3.312$, $p=0.073)$ 均无显著变化, 表现出较高的一致性(表2)。 其中蓝藻型地衣的内部含水量是绿藻型地衣的 2 倍 以上, $R s$ 表现出类似趋势。

\section{2 地衣功能群之间PV曲线及其参数的比较}

$\mathrm{PV}$ 曲线拟合结果(图1A-1F)显示, 双曲线拟合

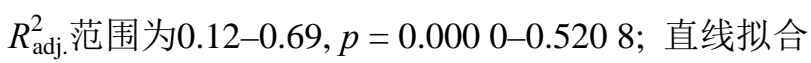

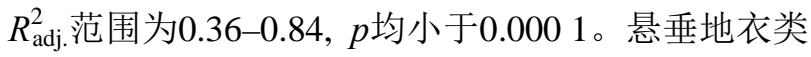
群明显具有更好的拟合性。其中, 蓝藻型地衣和阔 叶地衣PV曲线拟合中双曲线和直线不相交, 且 $p$ 值 均大于 0.05 。

不同功能群间地衣水势参数比较结果(表2)显 示, $W C_{\text {internal }}\left(\chi^{2}=28.48, p<0.001\right)$ 差异极其显著, 蓝藻型地衣(328.66\%干质量)最高, 悬垂、直立及狭 叶地衣较低(125.67\%-185.42\%干质量)。 $R s\left(\chi^{2}=\right.$ 29.21, $p<0.001)$ 和 $W C_{\text {internal }}$ 的变化趋势与其相同 (120.23\%-322.08\%干质量)。 $R W C_{\mathrm{TLP}}\left(\chi^{2}=17.158, p\right.$ $=0.002$ )差异极显著, 阔叶地衣(56.89\%)最高, 直立 地衣、蓝藻型地衣和狭叶地衣较低(39.15\%-45.75\%, 以上各物种之间 $p>0.05)$, 悬垂地衣(46.03\%)处于中 等水平。 $R a\left(\chi^{2}=6.282, p=0.179\right) 、 \Psi_{\text {TLP }}\left(\chi^{2}=9.421\right.$, $p=0.051)$ 及 $\Psi$ sat $\left(\chi^{2}=8.685, p=0.069\right)$ 均无显著性 差异。

\section{3 地衣物种间PV曲线及其参数的比较}

PV曲线拟合结果(图2)显示, 15种地衣的双曲线

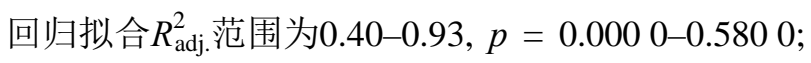

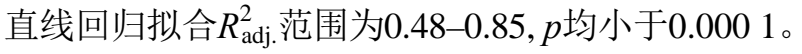
其中针芽肺衣 (Lobaria isidiophora) (双曲线 $R_{\text {adj. }}^{2}=$ 
0.88, $p=0.0012$; 直线 $R_{\text {adj. }}^{2}=0.85, p<0.0001$ ), 黑 腹绵腹衣 (Anzia hypomelaena) (双曲线 $R_{\text {adj. }}^{2}=0.85$, $p=0.004$; 直线 $\left.R_{\text {adj. }}^{2}=0.84, p<0.0001\right)$, 长松萝 (Usnea longissima)(双曲线 $R_{\text {adj. }}^{2}=0.84, p=0.06$; 直 线 $R_{\text {adj. }}^{2}=0.82, p<0.0001$ ) 具有较好的拟合性。

ANOVA和非参数检验结果显示, 地衣水势参数在 种间均有显著性差异。

不同地衣物种的 $W C_{\text {internal }}$ 差异极其显著(表 2; $\left.\chi^{2}=59.096, p<0.001\right)$ 。猫耳衣(Leptogium menziesii) (497.80\%干质量)和黑腹绵腹衣(349.87\%干质量)内 部含水量明显较高; 长松萝、卷梢哑铃狍(Hetero-
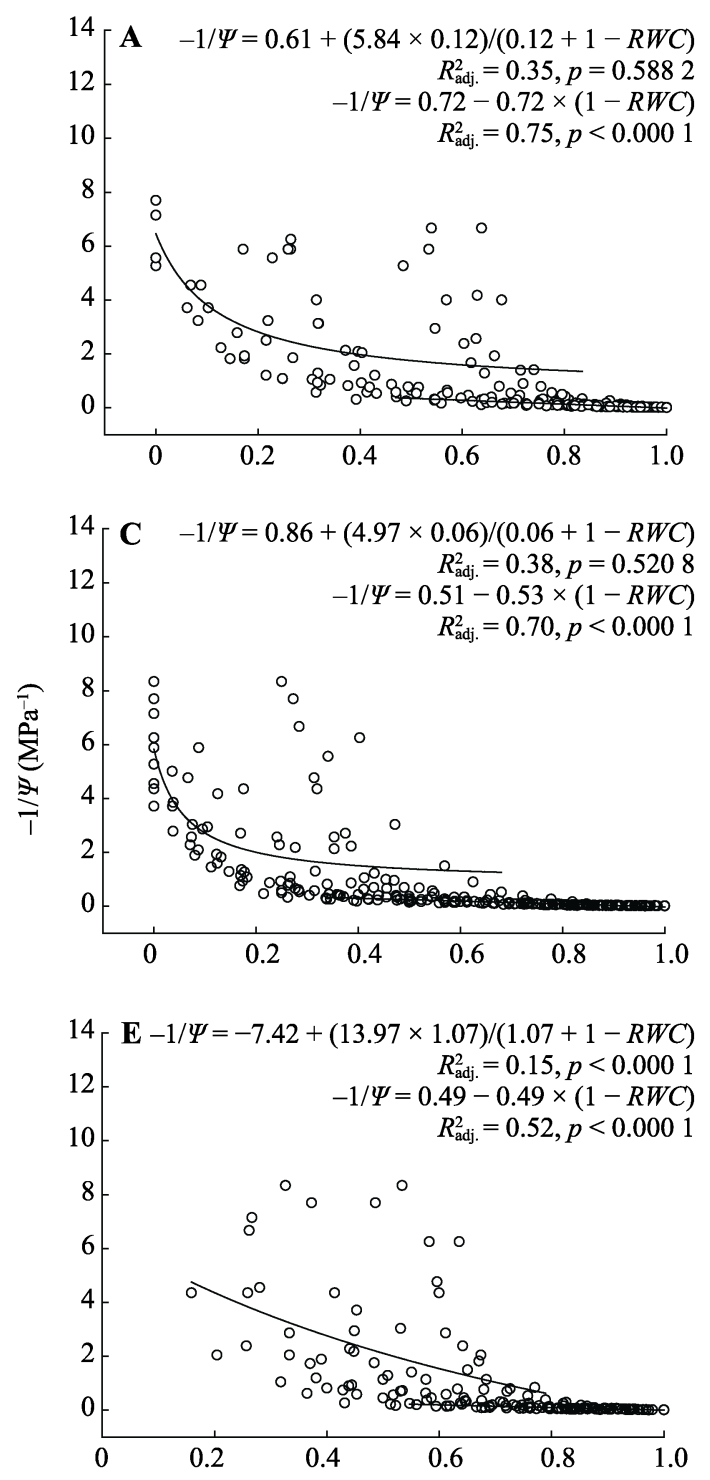

dermia boryi)、短根条衣(Everniastrum nepalense)及 网大叶梅 (Parmotrema reticulatum) 较低 $(97.86 \%-$ $119.18 \%$ 干质量, 各物种之间 $p>0.05$ ); 其余物种处 于中等水平 $(128.74 \%-349.87 \%$ 干质量)。而 $R s$ 的种间 变化趋势与其相同 $\left(\chi^{2}=58.626, p<0.001\right)$ 。

$R a$ 在各物种之间表现出差异极显著(表 $2 ; \chi^{2}=$ 26.112, $p=0.025)$ 。黑腹绵腹衣、平滑牛皮叶(Sticta nylanderiana)、黑芽牛皮叶(Sticta fuliginosa)、网肺 衣(Lobaria retigera)、云南袋衣(Hypogymnia yunnanensis)及网大叶梅质外体水较高(6.60\%-10.43\% 干质量, 各物种之间 $p>0.05$ ); 卷梢哑铃狍、槽枝衣
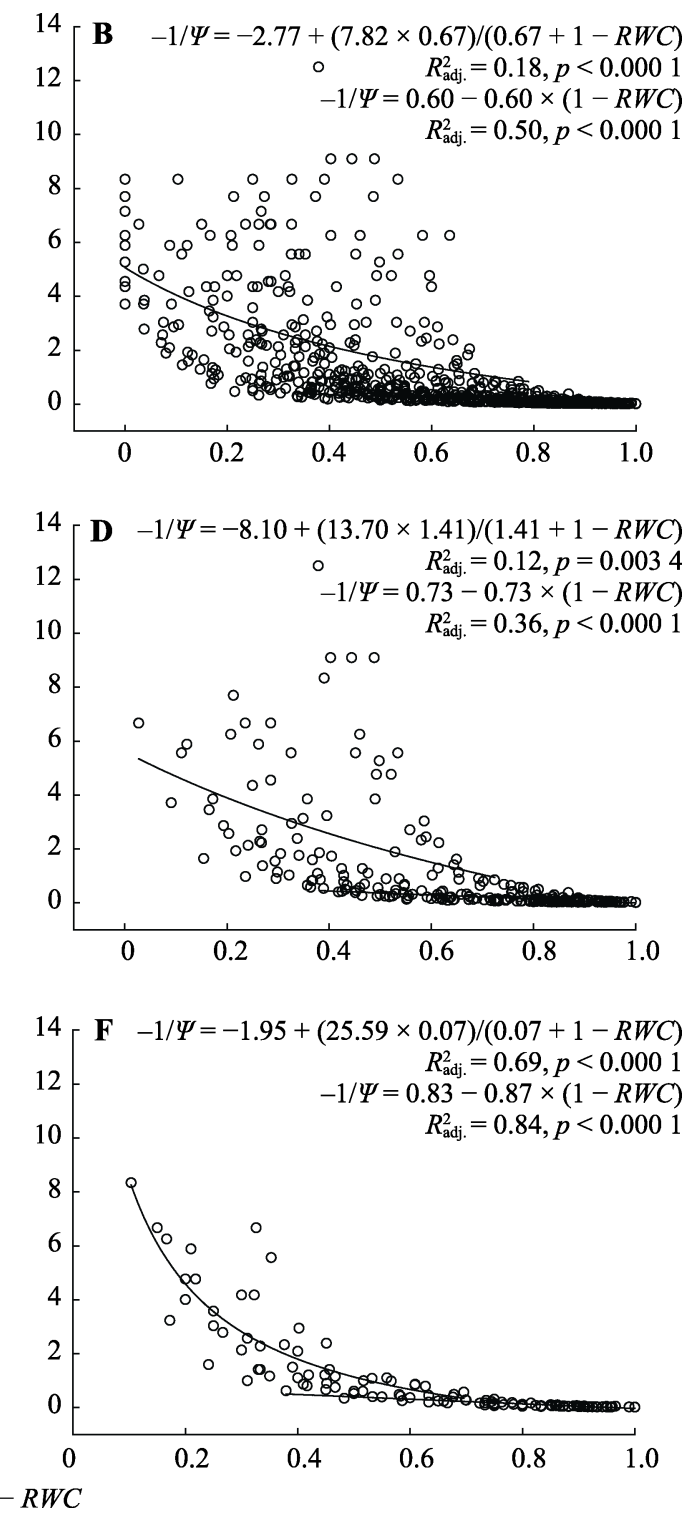

图1 云南哀牢山亚热带森林附生地衣功能群的压力-体积曲线。 $\mathrm{A}$, 蓝藻型地衣。 $\mathrm{B}$, 绿藻型地衣。 $\mathrm{C}$, 阔叶地衣。 $\mathrm{D}$, 狭叶地 衣。 $\mathbf{E}$, 直立地衣。 $\mathbf{F}$, 悬垂地衣。 $\Psi$, 水势; $R W C$, 相对含水量。

Fig. 1 Pressure-volume curves of epiphytic lichen functional groups in subtropical forests in the Ailao Mountains, Yunnan. A, Cyanolichens. B, Chlorolichens. C, Broadly lobed foliose chlorolichens. D, Narrowly lobed foliose chlorolichens. E, Shrubby fruticose chlorolichens. F, Pendent fruticose chlorolichens. $\Psi$, water potential; $R W C$, relative water content. 
表2 云南哀牢山亚热带森林附生地衣的水势参数(平均值土标准误)

Table 2 Water potential parameters (mean $\pm S E$ ) of epiphytic lichens in subtropical forests in the Ailao Mountains, Yunnan

\begin{tabular}{|c|c|c|c|c|c|c|c|c|}
\hline $\begin{array}{l}\text { 共生藻型 } \\
\text { Photobi-ont } \\
\text { type }\end{array}$ & $\begin{array}{l}\text { 生长型 } \\
\text { Growth form }\end{array}$ & 物种 Species & $\begin{array}{l}\text { 内部含水量 } \\
W C_{\text {internal }} \\
(\%, \text { Dry mass) }\end{array}$ & $\begin{array}{l}\text { 共质体水 } \\
R s \\
\text { (\%, Dry mass) }\end{array}$ & $\begin{array}{l}\text { 质外体水 } \\
R a \\
\text { (\%, Dry mass) }\end{array}$ & $\begin{array}{l}\text { 膨压损失点的 } \\
\text { 相对含水量 } \\
R W C_{\mathrm{TLP}}(\%)\end{array}$ & $\begin{array}{l}\text { 膨压损失点的 } \\
\text { 渗透势 } \Psi_{\mathrm{TLP}} \\
(\mathrm{MPa})\end{array}$ & $\begin{array}{l}\text { 饱和渗透势 } \\
\Psi \text { sat (MPa) }\end{array}$ \\
\hline \multirow{5}{*}{$\begin{array}{l}\text { 蓝藻 } \\
\text { Cyanob-acteria }\end{array}$} & & & $328.66 \pm 36.84^{\mathrm{Ac}}$ & $322.08 \pm 36.79^{\mathrm{Ac}}$ & $6.58 \pm 1.19^{\text {Aab }}$ & $40.96 \pm 3.97^{\mathrm{Abc}}$ & $-3.44 \pm 0.33^{\mathrm{Aa}}$ & $-1.29 \pm 0.13^{\mathrm{Aab}}$ \\
\hline & & & & & & & & \\
\hline & 叶状 Foliose & $\begin{array}{l}\text { 网肺衣 } \\
\text { Lobaria retigera }\end{array}$ & $214.86 \pm 11.54$ & $208.02 \pm 11.14$ & $6.85 \pm 2.64$ & $55.34 \pm 2.95$ & $-2.84 \pm 0.35$ & $-1.55 \pm 0.24$ \\
\hline & & $\begin{array}{l}\text { 猫耳衣 } \\
\text { Leptogium } \\
\text { menziesii }\end{array}$ & $497.80 \pm 43.93$ & $492.40 \pm 43.56$ & $5.40 \pm 1.44$ & $22.68 \pm 1.49$ & $-3.86 \pm 0.53$ & $-0.85 \pm 0.14$ \\
\hline & & $\begin{array}{l}\text { 黑芽牛皮叶 } \\
\text { Sticta fuliginosa }\end{array}$ & $273.31 \pm 32.08$ & $265.81 \pm 29.86$ & $7.49 \pm 2.30$ & $44.86 \pm 3.91$ & $-3.63 \pm 0.77$ & $-1.46 \pm 0.20$ \\
\hline \multirow{17}{*}{$\begin{array}{l}\text { 绿藻 } \\
\text { Green alga }\end{array}$} & & & $155.28 \pm 8.95^{\mathrm{B}}$ & $149.71 \pm 8.73^{\mathrm{B}}$ & $5.57 \pm 0.45^{\mathrm{A}}$ & $46.93 \pm 1.54^{\mathrm{A}}$ & $-3.80 \pm 0.22^{\mathrm{A}}$ & $-1.71 \pm 0.11^{\mathrm{A}}$ \\
\hline & $\begin{array}{l}\text { 阔叶型 } \\
\text { Broadly lobed } \\
\text { foliose }\end{array}$ & & $137.05 \pm 7.67^{\mathrm{ab}}$ & $130.05 \pm 7.18^{a b}$ & $7.00 \pm 0.80^{\mathrm{a}}$ & $56.89 \pm 2.73^{\mathrm{a}}$ & $-3.45 \pm 0.30^{\mathrm{a}}$ & $-1.89 \pm 0.18^{\mathrm{c}}$ \\
\hline & & $\begin{array}{l}\text { 针芽肺衣 } \\
\text { Lobaria } \\
\text { isidiophora }\end{array}$ & $133.11 \pm 10.40$ & $128.03 \pm 9.95$ & $5.08 \pm 1.20$ & $65.68 \pm 3.14$ & $-3.85 \pm 0.37$ & $-2.47 \pm 0.24$ \\
\hline & & $\begin{array}{l}\text { 网大叶梅 } \\
\text { Parmotrema } \\
\text { reticulatum }\end{array}$ & $119.18 \pm 12.49$ & $112.58 \pm 11.77$ & $6.60 \pm 0.79$ & $45.66 \pm 3.44$ & $-3.41 \pm 0.78$ & $-1.44 \pm 0.32$ \\
\hline & & $\begin{array}{l}\text { 平滑牛皮叶 } \\
\text { Sticta } \\
\text { nylanderiana }\end{array}$ & $158.87 \pm 12.26$ & $149.55 \pm 11.44$ & $9.32 \pm 1.57$ & $59.34 \pm 2.00$ & $-3.08 \pm 0.34$ & $-1.75 \pm 0.18$ \\
\hline & $\begin{array}{l}\text { 狭叶型 } \\
\text { Narrowly } \\
\text { lobed foliose }\end{array}$ & & $185.42 \pm 23.36^{\mathrm{ab}}$ & $179.71 \pm 22.70^{\mathrm{ab}}$ & $5.71 \pm 0.93^{\mathrm{ab}}$ & $45.75 \pm 2.23^{\mathrm{bc}}$ & $-3.74 \pm 0.43^{\mathrm{ab}}$ & $-1.72 \pm 0.23^{\mathrm{abc}}$ \\
\hline & & $\begin{array}{l}\text { 黑腹绵腹衣 } \\
\text { Anzia } \\
\text { hypomelaena }\end{array}$ & $349.87 \pm 25.89$ & $339.44 \pm 25.63$ & $10.43 \pm 1.08$ & $33.88 \pm 1.99$ & $-1.58 \pm 0.19$ & $-0.50 \pm 0.07$ \\
\hline & & $\begin{array}{l}\text { 短根条衣 } \\
\text { Everniastrum } \\
\text { nepalense }\end{array}$ & $115.29 \pm 6.35$ & $111.44 \pm 6.40$ & $3.86 \pm 0.40$ & $48.52 \pm 2.02$ & $-4.74 \pm 0.75$ & $-2.28 \pm 0.44$ \\
\hline & & $\begin{array}{l}\text { 卷梢哑铃狍 } \\
\text { Heterodermia } \\
\text { boryi }\end{array}$ & $109.69 \pm 9.46$ & $107.74 \pm 9.72$ & $1.95 \pm 0.46$ & $51.66 \pm 1.29$ & $-4.98 \pm 0.81$ & $-2.52 \pm 0.42$ \\
\hline & & $\begin{array}{l}\text { 云南袋衣 } \\
\text { Hypogymnia } \\
\text { yunnanensis }\end{array}$ & $166.81 \pm 7.57$ & $160.20 \pm 7.77$ & $6.61 \pm 2.20$ & $48.94 \pm 6.04$ & $-3.64 \pm 0.72$ & $-1.56 \pm 0.25$ \\
\hline & $\begin{array}{l}\text { 直立枝状 } \\
\text { Shrubby } \\
\text { fruticose }\end{array}$ & & $153.06 \pm 10.08^{\mathrm{a}}$ & $149.03 \pm 9.88^{\mathrm{a}}$ & $4.03 \pm 0.77^{\mathrm{b}}$ & $39.15 \pm 2.46^{\mathrm{c}}$ & $-4.82 \pm 0.45^{\mathrm{b}}$ & $-1.85 \pm 0.23^{\mathrm{bc}}$ \\
\hline & & $\begin{array}{l}\text { 裂髓树花 } \\
\text { Ramalina } \\
\text { conduplicans }\end{array}$ & $148.43 \pm 14.35$ & $142.97 \pm 13.80$ & $5.46 \pm 1.10$ & $48.02 \pm 2.01$ & $-5.82 \pm 0.89$ & $-2.70 \pm 0.42$ \\
\hline & & $\begin{array}{l}\text { 槽枝衣 } \\
\text { Sulcaria sulcata }\end{array}$ & $128.74 \pm 8.78$ & $125.69 \pm 8.03$ & $3.05 \pm 1.80$ & $40.92 \pm 2.38$ & $-3.97 \pm 0.54$ & $-1.56 \pm 0.16$ \\
\hline & & $\begin{array}{l}\text { 多花松萝 } \\
\text { Usnea florida }\end{array}$ & $182.00 \pm 20.55$ & $178.44 \pm 20.20$ & $3.57 \pm 0.96$ & $28.52 \pm 2.35$ & $-4.68 \pm 0.79$ & $-1.29 \pm 0.26$ \\
\hline & $\begin{array}{l}\text { 悬垂枝状 } \\
\text { Pendent } \\
\text { fruticose }\end{array}$ & & $125.67 \pm 10.85^{b}$ & $120.23 \pm 10.56^{\mathrm{b}}$ & $5.44 \pm 0.78^{\mathrm{ab}}$ & $46.03 \pm 3.63^{\mathrm{b}}$ & $-2.92 \pm 0.28^{\mathrm{a}}$ & $-1.19 \pm 0.06^{\mathrm{a}}$ \\
\hline & & $\begin{array}{l}\text { 巢松萝 } \\
\text { Usnea dasopoga }\end{array}$ & $153.47 \pm 10.12$ & $148.05 \pm 9.08$ & $5.43 \pm 1.20$ & $40.86 \pm 3.71$ & $-3.05 \pm 0.33$ & $-1.14 \pm 0.10$ \\
\hline & & $\begin{array}{l}\text { 长松萝 } \\
\text { Usnea longissima }\end{array}$ & $97.86 \pm 6.33$ & $92.41 \pm 5.72$ & $5.45 \pm 1.15$ & $51.20 \pm 5.65$ & $-2.79 \pm 0.48$ & $-1.24 \pm 0.08$ \\
\hline
\end{tabular}

不同字母表示差异显著 $(p<0.05)$ 。大写字母表示共生藻类型之间的比较, 小写字母表示不同功能群的比较。

$\Psi$ sat, saturation water osmotic potential; $\Psi_{\mathrm{TLP}}$, water potential at turgor loss point; $R a$, apoplastic water; $R s$, symplastic water; $R W C_{\mathrm{TLP}}$, relative water content at turgor loss point; $W C_{\text {internal, }}$ internal water content. Different letters indicate significant difference $(p<0.05)$, the uppercase letters indicate the comparison between different photobiont types, and the lowercase letters indicate the comparison between different functional groups. 

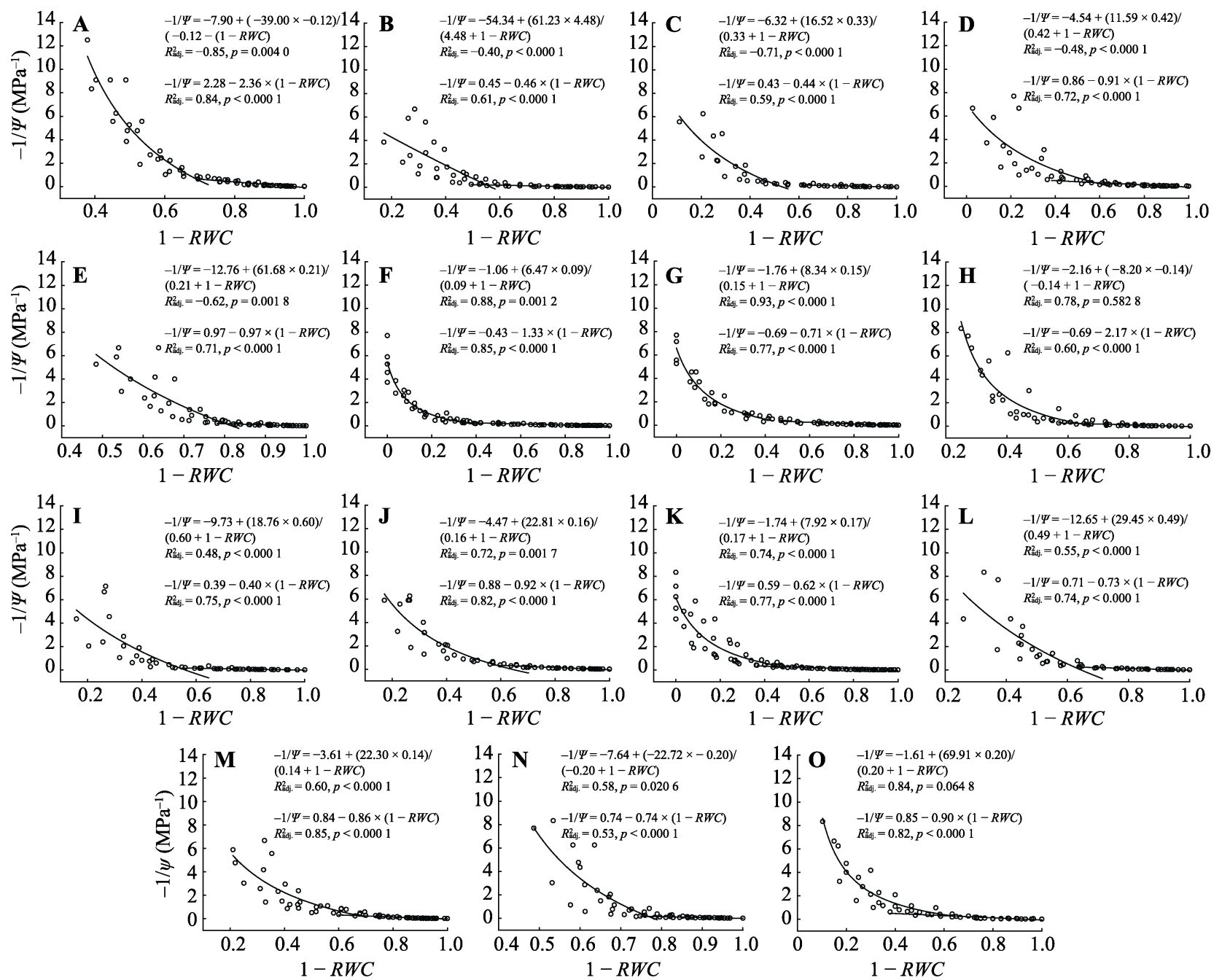

图2 云南哀牢山亚热带森林15种附生地衣的压力-体积曲线。 $\mathbf{A}$, 黑腹绵腹衣。 $\mathbf{B}$, 短根条衣。 $\mathbf{C}$, 卷梢哑铃狍。 $\mathbf{D}$, 云南袋衣。 E, 猫耳衣。 F, 针芽肺衣。G, 网肺衣。 H, 网大叶梅。 I, 裂髓树花。 J, 黑芽牛皮叶。 K, 平滑牛皮叶。 L, 槽枝衣。 $\mathbf{M}$, 巢松 萝。 $\mathbf{N}$, 多花松萝。 $\mathbf{O}$, 长松夢。 $\Psi$, 水势; $R W C$, 相对含水量。不同形状符号表示不同样品 $(n=5)$ 。

Fig. 2 Pressure-volume curves of 15 epiphytic lichens in subtropical forests in the Ailao Mountains, Yunnan. A, Anzia hypomelaena. B, Everniastrum nepalense. C, Heterodermia boryi. D, Hypogymnia yunnanensis. E, Leptogium menziesii. F, Lobaria isidiophora. G, Lobaria retigera. H, Parmotrema reticulatum. I, Ramalina conduplicans. J, Sticta fuliginosa. K, Sticta nylanderiana. L, Sulcaria sulcate. M, Usnea dasopoga. $\mathbf{N}$, Usnea florida. $\mathbf{O}$, Usnea longissima. $\Psi$, water potential; $R W C$, relative water content. Different symbols represent different samples $(n=5)$.

(Sulcaria sulcata) 和多花松萝(Usnea florida) 质外体 水较低(1.95\%-3.57\%干质量, 以上各物种之间 $p>$ $0.05)$, 其余物种处于中等水平(3.86\%-5.46\%干质量)。

$R W C_{\mathrm{TLP}}$ 的物种间差异极其显著 (表 2; $\chi^{2}=$ $52.315, p<0.001)$ 。针芽肺衣 $(65.68 \%)$ 显著较高, 猫 耳衣和多花松萝的 $R W C_{\mathrm{TLP}}(22.68 \%-28.52 \%)$ 显著低 于其余物种(33.88\%-59.34\%)。

$\Psi_{\mathrm{TLP}}$ 的物种间差异极显著 (表2; $F=2.881, p=$ 0.002)。 $\Psi_{\mathrm{TLP}}$ 的范围从-1.58 MPa (黑腹绵腹衣)到 -5.82 MPa (裂髓树花Ramalina conduplicans)。黑腹 绵腹衣、长松夢、网肺衣、巢松萝(Usnea dasopoga) 和平滑牛皮叶 $\Psi_{\mathrm{TLP}}$ 较高( $-3.08--1.58 \mathrm{MPa}$, 以上各
物种之间 $p>0.05)$ 。裂髓树花、卷梢哑铃狍、短根 条衣和多花松夢的 $\Psi_{\mathrm{TLP}}$ 较低(-5.82- -4.68 MPa以上 各物种之间 $p>0.05)$ 。其余物种处于中等水平 $(-3.97--3.41 \mathrm{MPa})$ 。

$\Psi$ sat的物种间差异极其显著 $(F=5.783, p<$ 0.001)。 $\Psi$ sat变化范围为 $-0.50--2.70 \mathrm{MPa}$, 其中裂 髓树花、卷梢亚铃狍、针芽肺衣和短根条衣 $\Psi$ sat值 较低(以上各物种之间 $p>0.05$ ); 相反, 黑腹绵腹衣、 猫耳衣、巢松萝和长松萝有较高的 $\Psi$ sat (以上各物种 之间 $p>0.05$ )。

\subsection{PCA分析}

水势参数相关性计算显示(附录II), $W C_{\text {internal }}$ 和 
$R s(r=0.997) 、 \Psi_{\mathrm{sat}}$ 和 $\Psi_{\mathrm{TLP}}(r=0.807)$ 高度相关。因 此, 2 组高共线因子中, 保留 $R s$ 和 $\Psi$ sat用于PCA分析。

PCA分析(表3; 图3)显示, 仅前 2 个主成分特征 值(1.451和1.038)大于 1 , 方差解释率分别为 $52.66 \%$ 和 $26.94 \%$, 累计79.60\%。PC1主要由Rs (0.584)和 $\Psi \mathrm{sat}$ (0.566)载荷, 说明地衣物种由左(针芽肺衣和卷梢哑 铃孢)到右(猫耳衣和黑腹绵腹衣)内部最大持水力可 能表现出逐渐增加的变化趋势; PC2 主要由 $R a$ $(-0.818)$ 和 $R W C_{\mathrm{TLP}}(-0.565)$ 载荷, 暗示了地衣物种由 下(猫耳衣和多花松萝)到上(平滑牛皮叶)细胞质壁分 离发生时水分含量可能表现出逐渐增加的变化趋势。

\section{3 讨论}

\section{1 不同植物类群PV曲线参数变化分析}

本研究显示, 附生地衣 $R W C_{\mathrm{TLP}}$ 的范围是 $22.68 \%$ (猫耳衣)-65.68\% (针芽肺衣), $\Psi_{\mathrm{TLP}}$ 和 $\Psi \mathrm{sat}$ 的 范围分别为-1.58 MPa (黑腹绵腹衣) - $-5.82 \mathrm{MPa}$ (裂髓树花)以及-0.50 MPa (黑腹绵腹衣) - - 2.70 MPa (裂髓树花)。Nardini等(2013)对6种地卷属 (Peltigera) 地衣的研究显示, $\Psi_{\mathrm{TLP}}$ 的范围为-1.16 MPa (白腹地卷 $(P$. leucophlebia) $--3.19 \mathrm{MPa}$ (地卷 (P. rufescens)); 且在嗜湿性地衣中 $\Psi_{\mathrm{TLP}}>-2.0 \mathrm{MPa}$, 嗜干性地衣中 $\Psi_{\mathrm{TLP}}<-2.5 \mathrm{MPa}$ 。 $\Psi_{\mathrm{s} a t}$ 的范围为 -0.62 $\mathrm{MPa}$ (白腹地卷) $--1.55 \mathrm{MPa}$ (地卷); 在嗜湿性地衣 中 $\Psi$ sat $>-0.9 \mathrm{MPa}$, 嗜干性地衣中 $\Psi$ sat $<-1.3 \mathrm{MPa}$; 本研究结果范围与之接近。但地卷属地衣 $\Psi_{\mathrm{TLP}}$ 更 大, $\Psi$ sat范围更小, 说明本实验涉及的地衣物种或 许具有更强的抗旱性。相比较而言, 草本植物各水 势参数变化范围分别为 $R W C_{\mathrm{TLP}}$ : $28.12 \%-39.49 \%$, $\Psi_{\mathrm{TLP}}$ : $-1.78--3.69 \mathrm{MPa}, \Psi$ sat: $-1.01--3.02 \mathrm{MPa}$ 表3 云南哀牢山亚热带森林15种附生地衣水势参数在主成分分析(PCA) 中的载荷和解释方差

Table 3 Principal component analysis (PCA) loading and interpretation variances of water potential parameters of 15 epiphytic lichens in subtropical forests in the Ailao Mountains, Yunnan

\begin{tabular}{lcc}
\hline 水势参数 Water potential parameter & PC1 & PC2 \\
\hline 共质体水 $R s$ & 0.584 & - \\
质外体水 $R a$ & 0.307 & -0.818 \\
质壁分离时相对含水量 $R W C_{\mathrm{TLP}}$ & -0.494 & -0.565 \\
饱和渗透势 $\Psi$ sat & 0.566 & - \\
标准差 Standard deviation & 1.451 & 1.038 \\
方差贡献率 Proportion of variance & $52.66 \%$ & $26.94 \%$ \\
方差累计贡献率 Cumulative proportion & $52.66 \%$ & $79.60 \%$ \\
\hline
\end{tabular}

sat, saturation water osmotic potential; $R a$, apoplastic water; $R s$, symplastic water; $R W C_{\mathrm{TLP}}$, relative water content at turgor loss point.

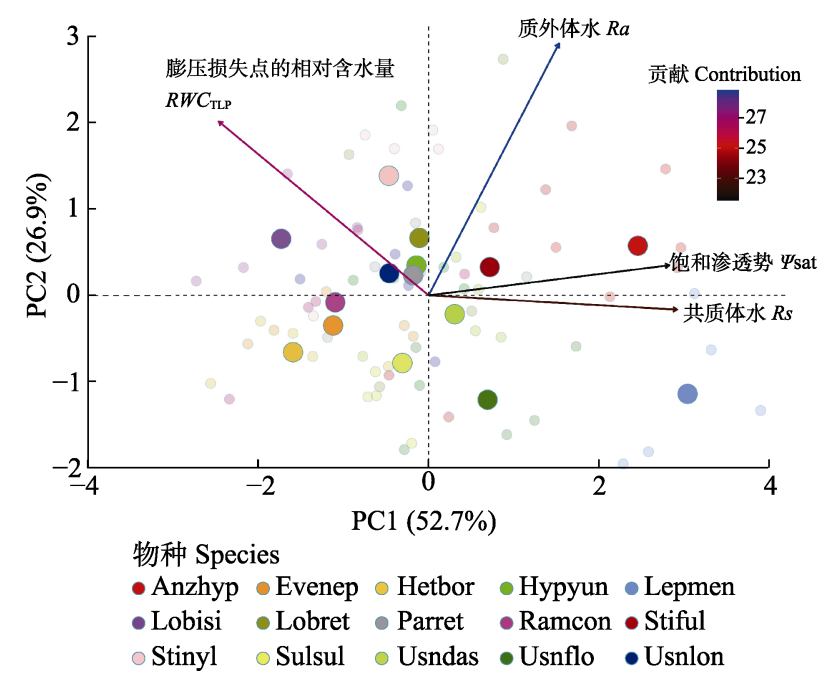

图3 云南哀牢山亚热带森林15种附生地衣水势参数的主成 分分析(PCA)。Anzhyp, 黑腹绵腹衣; Evenep, 短根条衣; Hetbor, 卷梢哑铃狍; Hypyun, 云南袋衣; Lepmen, 猫耳衣; Lobisi, 针芽肺衣; Lobret, 网肺衣; Parret, 网大叶梅; Ramcon, 裂髓树花; Stiful, 黑芽牛皮叶; Stinyl, 平滑牛皮叶; Sulsul, 槽枝衣; Usndas, 巢松萝; Usnflo, 多花松夢; Usnlon, 长松萝;

Fig. 3 Principal component analysis (PCA) plots of water potential parameters of 15 epiphytic lichens in subtropical forests in the Ailao Mountains, Yunnan. Anzhyp, Anzia hypomelaena; Evenep, Everniastrum nepalense; Hetbor, Heterodermia boryi; Hypyun, Hypogymnia yunnanensis; Lepmen, Leptogium menziesii; Lobisi, Lobaria isidiophora; Lobret, Lobaria retigera; Parret, Parmotrema reticulatum; Ramcon, Ramalina conduplicans; Stiful, Sticta fuliginosa; Stinyl, Sticta nylanderiana; Sulsul, Sulcaria sulcate; Usndas, Usnea dasopoga; Usnflo, Usnea florida; Usnlon, Usnea longissima. Ysat, saturation water osmotic potential; $R a$, apoplastic water; $R s$, symplastic water; $R W C_{\mathrm{TLP}}$, relative water content at turgor loss point.

(He et al., 2007); 灌木各水势参数变化范围分别为 $R W C_{\mathrm{TLP}}: 81.00 \%-89.01 \%, \Psi_{\mathrm{TLP}}:-3.19--3.49 \mathrm{MPa}$, Ysat: -2.47--2.90 MPa (Yan et al., 2013); 乔木各水 势参数变化范围分别为 $R W C_{\mathrm{TLP}}$ : $85.29 \%-93.00 \%$, $\Psi_{\text {TLP }}$ : $-2.19--3.28 \mathrm{MPa}, \Psi$ sat: $-1.80--2.52 \mathrm{MPa}$ (Castro-Díez \& Navarro, 2007; Yan et al., 2013); 可 以看出附生地衣 $R W C_{\mathrm{TLP}}$ 显著低于灌木和乔木, 高 于草本(单样本 $t$ 检验见附录III, 下同), 说明在忍耐 脱水能力方面, 或许草本>附生地衣>灌木>乔木。附 生地衣 $\Psi_{\mathrm{TLP}}$ 值均显著低于草本、灌木及乔木(附录 III), 说明附生地衣相对于高等植物而言, 应对环境 不同强度的干旱胁迫时, 可能具有更灵活多变的适 应策略。附生地衣 $\Psi$ sat值与草本范围大致相同, 均 显著高于灌木和乔木(附录III)。上述特征和地衣作 为变水性类群的特性是一致的, 也可能是附生地衣 能在极端干旱环境中生长的原因(Nash, 2008)。而 
Song等(2015)研究了哀牢山同一地区原生林内树平 藓 (Homaliodendron flabellatum) 、树 形羽苔 (Plagiochila arbuscula)及阿萨羽苔(Plagiochila assamica) 3 种附生苔藓的水势参数, $R W C_{\mathrm{TLP}}$ 为 63.9\%-67.4\%, $\Psi_{\mathrm{TLP}}$ 为-2.6- -4.2 MPa, $\Psi_{\text {sat }}$ 为-1.6$-2.5 \mathrm{MPa}$ 。附生地衣 $R W C_{\mathrm{TLP}}$ 和 $\Psi_{\mathrm{TLP}}$ 显著低于苔藓, $\Psi$ sat显著高于苔蘚(附录III), 暗示了附生地衣可能 比苔藓对干旱环境具有更强的适应性, 这也解释了 哀牢山地区地衣类群的生境复杂多样、相对苔藓更 适应干旱生境的现象(Li et al., 2013a; Song et al., 2015)。

\section{2 蓝藻型和绿藻型地衣PV曲线参数变化分析}

蓝藻型地衣和绿藻型地衣 $W C_{\text {internal }}$ 和 $R s$ 表现出 显著差异, 暗示了 $W C_{\text {internal }}$ 和 $R s$ 可能是两类地衣适 应外界水分环境的重要参数。其他水势参数没有表 现出显著差异, 体现了地衣作为变水类群较高的一 致性。蓝藻型地衣 $W C_{\text {internal }}$ 明显高于绿藻型地衣, 表 明它们对内部含水量的依赖程度不同。研究显示, 蓝藻型地衣只能利用液态水进行光合作用(Lange \& Ziegler, 1986), 更偏好潮湿生境。而其共生藻细胞外 存在一层较厚的凝胶状保护鞘(Honegger et al., 1996; Gauslaa \& Coxson, 2011), 并可以通过凝胶状 物质提高持水量, 抵御水分胁迫。而绿藻型地衣更 倾向于通过快速交换或快速吸收水分等应对外界水 分条件的变化(Hartard et al., 2009)。蓝藻型地衣(以 及阔叶地衣) PV曲线出现双曲线和直线拟合不相交 的现象, 结合蓝藻地衣物种的 PV曲线, 推测是蓝藻 型地衣物种间 $R W C_{\mathrm{TLP}}$ 变异较大所致。

\section{3 附生地衣功能群间PV曲线参数变化分析}

地衣水势参数 $W C_{\text {internal }}$ 和 $R s$ 在各功能群之间的 差异表现出一致性。即使同为枝状地衣的直立地衣 和悬垂地衣, 也表现出显著差异; 这可能和二者的 水分存储策略差异有关(Eriksson et al., 2018)。哀牢 山地区的前期研究(Li et al., 2013a; 陈克等, 2014; 胡涛等, 2016)显示, 蓝藻地衣广泛分布于阴湿生境, 但水分条件较好时, 部分个体也能够在高光生境内 生存; 枝状地衣较多分布于干燥高光生境; 阔叶和 狭叶型地衣广泛分布于光照较充足的生境中(如林 冠层、林缘、林外灌从或杂树丛), 但前者对水分条 件要求更高, 多分布于较为潮湿的生境。本研究结 果与上述发现并不完全对应, 如狭叶地衣内部含水
量高于阔叶地衣。但不包括黑腹绵腹衣的狭叶地衣 内部含水量为 $130.60 \% \pm 8.06 \%$, 低于阔叶地衣, 说 明本研究中狭叶地衣类群较高的内部含水量均值主 要是受黑腹绵腹衣的偏差所致。而且, 叶状地衣比 枝状地衣(直立地衣除外)具有更高的内部含水量, 说明其比后者拥有更高的持水量和水分存储能力, 更好地延长生理活动时间(Lange \& Ziegler, 1986)。 枝状地衣具有更大的体表面积比, 这种形态特征也 使得它们能够从湿润的空气中快速地吸收水分和交 换水分(Lange \& Ziegler, 1986), 从而能够适应林外 干燥的环境。以上研究也表明, 不同功能群基于内 部含水量的参数变化, 仅仅是地衣类群适应水分变 化的策略之一。

$R W C_{\mathrm{TLP}}$ 常用于衡量植物应对干旱胁迫的能力。 $R W C_{\mathrm{TLP}}$ 越低, 植物抗旱性越强。但对于地衣类群而 言, 似乎并非如此。如阔叶地衣 $R W C_{\mathrm{TLP}}$ 显著高于其 他功能群 $(0.002<p<0.02)$, 若表示其抗旱性在所 有功能群中最弱, 却与其生境选择并不一致。且同 为枝状地衣的悬垂地衣 $R W C_{\mathrm{TLP}}$ 显著高于直立地衣, 似乎说明直立地衣比悬垂地衣更加抗旱, 但二者的 附生类群在野外更倾向于生长在一起。因此, $R W C_{\mathrm{TLP}}$ 是否能够用于不同功能群附生地衣的抗旱 性比较, 仍有待商榷。

\section{4 附生地衣物种间PV曲线参数变化分析}

本研究发现, 地衣物种之间PV曲线参数均具 有显著性差异。如猫耳衣(497.80\%干质量)和黑腹绵 腹衣(349.87\%干质量)的 $W C_{\text {internal }}\left(R s\right.$ 是 $W C_{\text {internal }}$ 的主 要组成部分, 具有相同趋势) 明显高于其他附生地 衣, 而长松夢、卷梢亚铃狍、短根条衣及网大叶梅 (97.86\%-119.18\%干质量)的 $W C_{\text {internal }}$ 较低, 说明前 者可能更依赖于内部含水量抵御干旱胁迫, 后者在 抵御干旱胁迫时内部含水量发挥的作用更小。黑腹

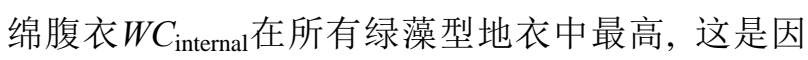
为绵腹衣属(Anzia)地衣没有下皮层, 但下表面具有 非常独特的裸露的较厚菌丝层, 类似海绵组织, 能 吸收和存储大量的水分(王立松, 1995)。狭叶类群中, 云南袋衣(166.81\%干质量)的 $W C_{\text {internal }}$ 比短根条衣 (115.29\%干质量)和卷梢哑铃孢(109.69\%干质量)更 高, 可能是因为云南袋衣通过增加叶状体厚度、宽 度及扩大细胞间隙来增加持水量和降低失水速率 (胡涛等, 2016)。其他水势参数在不同物种间虽表现 
出显著差异, 但不同水势参数生态学含义与各地衣 物种对生境的选择并不相符。

\subsection{PV曲线及相关参数在地衣水分特性评估中的 适用性}

根据前人研究(Li et al., 2013a; 陈克等, 2014; 胡涛等, 2016) 以及野外观察, 结合PCA结果, 研究 认为, PV曲线及相关参数在评估地衣类群整体的抗 旱能力时, 具有明显的限制性。然而, 对于比较同一 类群内部地衣物种对环境水分条件的适应性来说, 个别参数具有较好的适用性。如PCA中, PC1所代表 的由左到右内部最大持水力逐渐增加的变化趋势, 可以解释蓝藻型地衣对生境的适应能力, 即猫耳衣 偏好阴湿生境、黑芽牛皮叶生活于潮湿高光生境以 及网肺衣生境复杂多样的现象(表1)。但PC1并不能 很好地解释绿藻型地衣基于水分条件变化的生境选 择策略, 如裂髓树花和黑腹绵腹衣多分布于高光生 境, 但被分散到PC1轴左右两端; 这可能与绿藻型 地衣生长型多变、水分利用策略多样有关(Vries \& Watling, 2008; Esseen et al., 2017)。然而, Ysat可以很 好地解释狭叶地衣的生境适应选择策略。如卷梢哑 铃孢裂片呈条带状, 形态接近于枝状地衣, 适宜高 光干燥生境, 短根条衣、云南袋衣及黑腹绵腹衣地 衣体逐渐变厚, 沿 $\Psi$ sat箭头方向饱和水势逐渐增加, 抗旱性逐渐减弱。 $R W C_{\mathrm{TLP}}$ 可以分别用于阔叶地衣和 枝状地衣环境水分条件适应能力的解释, 沿 $R W C_{\mathrm{TLP}}$ 箭头方向各物种相对含水量逐渐增加, 抗 旱性减弱。阔叶地衣中, 针芽肺衣、平滑牛皮叶和 网大叶梅逆 $R W C_{\mathrm{TLP}}$ 箭头方向地衣体逐渐变薄变小, 更加适应干燥生境; 而在枝状地衣中, 长松萝多生 长于高光潮湿生境(Eriksson et al., 2018), 多花松夢 更适宜林外高光干燥生境。

综上所述, 地衣对环境水分条件的适应策略的 高度多样性(Li et al., 2011; Esseen et al., 2017; Longinotti et al., 2017), 导致基于内部含水量的PV 曲线及部分相关水势参数, 在被用于评估地衣的水 分适应特征以及基于水分条件的生境选择时, 必须 考虑到共生藻型和生长型的显著影响, 谨慎用于整 体地衣的抗旱性评价。而且, 抗旱性作为生物的复 合性状, 是形态解剖构造、生理生化和原生质特性 以及水分生理生态特征、生理生化反应的综合反映 (王孟本等, 1999), 单一指标多不能很好地反映植物 的抗旱性。对于地衣类群而言, 其生态学研究资料
的长期匮乏以及类群的特殊性, 导致我们对于常规 分析方法和常用指标在地衣类群中的适用性均缺乏 足够的了解, 这也提醒我们在进行地衣和其他生物 类群比较时, 慎用相关水势参数。同时, 我们也需要 在地衣类群的水分利用策略方面(如水分储存和交 换方式等), 开展更加深入的研究, 以期准确揭示地 衣类群的水分利用策略。

致谢 感谢中国科学院哀牢山亚热带森林生态系统 研究站以及高有财和胡小文先生在野外工作中给予 的帮助。

\section{参考文献}

Barkman JJ (1958). Phytosociology and Ecology of Cryptogamic Epiphytes. van Gorcum, Assen, Netherlands.

Beckett RP (1997). Pressure-volume analysis of a range of poikilohydric plants implies the existence of negative turgor in vegetative cells. Annals of Botany, 79, 145-152.

Cai JR, Qian TH, Lei JL (2015). Evaluation of drought resistance of five wild shrub species in South China. Ecological Science, 34, 94-103. [蔡静如, 钱瑭璜, 雷江丽 (2015). 华南地区5 种野生灌木的抗旱性评价. 生态科 学, 34, 94-103.]

Castro-Díez P, Navarro J (2007). Water relations of seedlings of three Quercus species: variations across and within species grown in contrasting light and water regimes. Tree Physiology, 27, 1011-1018.

Chen K, Liu WY, Li S, Song L (2014). Photosynthetic characteristics of three epiphytic lichens under different water conditions. Plant Diversity and Resources, 36, 603-610. [陈克, 刘文耀, 李苏, 宋亮 (2014). 不同水分条件下三 种附生地衣的光合作用特性. 植物分类与资源学报, 36, 603-610.]

Eriksson A, Gauslaa Y, Palmqvist K, Ekström M, Esseen PA (2018). Morphology drives water storage traits in the globally widespread lichen genus Usnea. Fungal Ecology, 35, 51-61.

Esseen PA, Rönnqvist M, Gauslaa Y, Coxson DS (2017). Externally held water-A key factor for hair lichens in boreal forest canopies. Fungal Ecology, 30, 29-38.

Gauslaa Y, Coxson DS (2011). Interspecific and intraspecific variations in water storage in epiphytic old forest foliose lichens. Botany, 89, 787-798.

Hartard B, Cuntz M, Máguas C, Lakatos M (2009). Water isotopes in desiccating lichens. Planta, 231, 179-193.

He XD, Cong PF, Gao YB, Lu JG, Wang HT, Xue PP, Zhang X (2007). Drought resistance of four grasses using pressurevolume curve. Frontiers of Biology in China, 2, 425-430.

Honegger R, Peter M, Scherrer S (1996). Drought-induced structural alterations at the mycobiont-photobiont interface 
in a range of foliose macrolichens. Protoplasma, 190, 221-232.

Hu T, Li S, Liu S, Liu WY, Chen X, Song L, Chen Q (2016). Water relations and photosynthetic characteristics in different functional groups of epiphytic lichens in montane forest of Ailaoshan. Chinese Journal of Plant Ecology, 40, 810-826. [胡涛, 李苏, 柳帅, 刘文耀, 陈㬢, 宋亮, 陈泉 (2016). 哀牢山山地森林不同附生地衣功能群的水分关 系和光合生理特征. 植物生态学报, 40, 810-826.]

Lange OL (2003). Photosynthetic productivity if the epilithic lichen Lecanora muralis: long-term field monitoring of $\mathrm{CO}_{2}$ exchanges physiological interpretation. Diel, seasonal, and annual carbon budgets. Flora, 198, 277-292.

Lange OL, Ziegler H (1986). Different Limiting Processes of Photosynthesis in Lichens. Biological Control of Photosynthesis. Martinus Nijhoff Publishers, Dordrecht. 147-161.

Li HJ, Di XY, Chen JW, Wang MB (2004). A method of using SigmaPlot to calculate the moisture parameter $\Psi_{\text {TLP }}$ of the PV curve. Plant Research, 24, 71-75. [李洪建, 狄晓艳, 陈建文, 王孟本 (2004). 一种用SigmaPlot求PV曲线水 分参数 $\Psi_{\mathrm{TLP}}$ 的方法. 植物研究, 24, 71-75.]

Li S, Liu WY, Li DW (2013a). Bole epiphytic lichens as potential indicators of environmental change in subtropical forest ecosystems in southwest China. Ecological Indicators, 29, 93-104.

Li S, Liu WY, Li DW (2013b). Epiphytic lichens in subtropical forest ecosystems in southwest China: species diversity and implications for conservation. Biological Conservation, 159, 88-95.

Li S, Liu WY, Wang LS, Ma WZ, Song L (2011). Biomass, diversity and composition of epiphytic macrolichens in primary and secondary forests in the subtropical Ailao Mountains, SW China. Forest Ecology and Management, 261, 1760-1770.

Li S, Liu WY, Wang LS, Yang GP, Li DW (2007). Species diversity and distribution of epiphytic lichens in the primary and secondary forests in Ailao Mountain, Yunnan. Biodiversity Science, 15, 445-455. [李苏, 刘文耀, 王立 松, 杨国平, 李达文 (2007). 云南哀牢山原生林及次生 林群落附生地衣物种多样性与分布. 生物多样性, 15, 445-455.]

Longinotti S, Solhaug K, Gauslaa Y (2017). Hydration traits in cephalolichen members of the epiphytic old forest genus Lobaria (s. lat.). The Lichenologist, 49, 493-596.

McCune B (1993). Gradients in epiphyte biomass in three Pseudotsuga-Tsuga forests of different ages in western Oregon and Washington. The Bryologist, 96, 405-411.

Motalebifard R, Najafi N, Oustan S, Nyshabouri MR, Valizadeh $M$ (2013). The combined effects of phosphorus and zinc on evapotranspiration, leaf water potential, water use efficiency and tuber attributes of potato under water deficit conditions. Scientia Horticulturae, 162, 31-38.
Nardini A, Marchetto A, Tretiach M (2013). Water relation parameters of six Peltigera species correlate with their habitat preferences. Fungal Ecology, 6, 397-407.

Nash TH (2008). Lichen Biology. 2nd ed. Cambridge University Press, Cambridge, UK.

Nimis PL, Martellos S (2008). ITALIC-The Information System on Italian Lichens. Version 4.0. [2015-12-07]. http://dbiodbs. univ.trieste.it/.

Olson DM, Dinerstein E (1998). The global 200: a representation approach to conserving the earth's most biologically valuable ecoregions. Conservation Biology, 12, 502-515.

Saruwatari MW, Davis SD (1989). Tissue water relations of three chaparral shrub species after wildfire. Oecologia, 80, 303-308.

Sato T, Abdalla OS, Oweis TY, Sakuratani T (2006). The validity of predawn leaf water potential as an irrigationtiming indicator for field-grown wheat in northern Syria. Agricultural Water Management, 82, 223-236.

Smith DC, Molesworth S (1973). Lichen physiology xiii. Effects of rewetting dry lichens. New Phytologist, 72, 525-533.

Song L, Zhang YJ, Chen X, Li S, Lu HZ, Wu CS, Tan ZH, Liu WY, Shi XM (2015). Water relations and gas exchange of fan bryophytes and their adaptations to microhabitats in an Asian subtropical montane cloud forest. Journal of Plant Research, 128, 573-584.

Tyree MT, Hammel HT (1972). The measurement of the turgor pressure and the water relations of plants by the pressurebomb technique. Journal of Experimental Botany, 23, 267-282.

Vries MC, Watling JR (2008). Differences in the utilization of water vapour and free water in two co-occurring foliose lichens from semi-arid southern Australia. Austral Ecology, 33, 975-985.

Wang LS (1995). Anzia physowea, a lichen new to China. Mycosystema，14，313-314. [王立松 (1995). 棒根绵腹衣在 我国的首次发现. 真菌学报, 14, 313-314.]

Wang MB, Li HJ, Chai BF, Wu DM (1999). Drought resistance index of tree species in the loess region. Bulletin of Botanical Research, 19, 341-346. [王孟本, 李洪建, 柴宝峰, 武冬梅 (1999). 黄土区树种抗旱性指数的研究. 植物研 究, 19, 341-346.]

Wenkert W, Lemon ER, Sinclair TR (1978). Water content potential relationship in soya bean: changes in component potentials for mature and immature leaves under field conditions. Annals of Botany, 42, 295-307.

Yan MJ, Yamamoto M, Yamanaka N, Yamamoto F, Liu GB, Du S (2013). A comparison of pressure-volume curves with and without rehydration pretreatment in eight woody species of the semiarid Loess Plateau. Acta Physiologiae Plantarum, 35, 1051-1060.

Zhang LS, Zhang HT, Hu JJ, Quan J, Xu SR, Han MY, Ma FW (2013). The response of pressure volume curve water

www.plant-ecology.com 
parameters and root system hydraulic architecture of two apple rootstocks to drought stress. Acta Ecologica Sinica, 33, 3324-3331. [张林森, 张海亭, 胡景江, 权静, 胥生 荣, 韩明玉, 马锋旺 (2013). 两种苹果砧木根系水力结 构及其PV曲线水分参数对干旱胁迫的响应. 生态学报, 33, 3324-3331.]

Zheng YX, Wu JC, Cao FL, Zhang YP (2010). Effects of water stress on photosynthetic activity, dry mass partitioning and some associated metabolic changes in four provenances of neem (Azadirachta indica A. Juss). Photosynthetica, 48, 361-369.

Zhu H, Yan LC (2009). List of Seed Plants in the Ailao Mts. of Yunnan Province, China. Yunnan Science and Technology Press, Kunming. [朱华, 间丽春 (2009). 云南哀牢山种 子植物. 云南科技出版社, 昆明.]

责任编委: 李 彦 责任编辑: 李 敏

\section{附录I PV曲线的相关水势参数}

Supplement I Related water potential parameters of PV curve

https://www.plant-ecology.com/fileup/1005-264X/PDF/cjpe.2020.0344-S1.pdf

附录II 云南哀牢山亚热带森林15种附生地衣水势参数的相关性

Supplement II Correlations for water potential parameters across 15 epiphytic lichens in subtropical forests in the Ailao Mountains, Yunnan

https://www.plant-ecology.com/fileup/1005-264X/PDF/cjpe.2020.0344-S2.pdf

附录III 云南哀牢山亚热带森林附生地衣与其他研究中不同植物类群PV曲线参数单样本 $t$ 检验(平均值 \pm 标准误)

Supplement III PV curve parameters of epiphytic lichens in subtropical forests in the Ailao Mountains in Yunnan and results of one sample $t$-test between liches and other plant growth forms (mean $\pm S E$ )

https://www.plant-ecology.com/fileup/1005-264X/PDF/cjpe.2020.0344-S3.pdf 
董琳琳，普晓妍，张璐璐，宋亮，鲁志云，李苏 (2021). 亚热带森林附生地衣压力-体积曲线分析及其适用性. 植物生态学报, 45, 274-285. DOI: 10.17521/cjpe.2020.0344

Dong LL, Pu XY, Zhang LL, Song L, Lu ZY, Li S (2021). Pressure-volume curve analysis of epiphytic lichens and its applicability in subtropical forests. Chinese Journal of Plant Ecology, 45, 274-285. DOI: 10.17521/cjpe. 2020.0344

https://www.plant-ecology.com/CN/10.17521/cjpe.2020.0344

附录I 压力-体积曲线的相关水势参数

Supplement I Related water potential parameters of Pressure-volume curve

\begin{tabular}{lll}
\hline 参数 Parameter & 单位 Unit & 生态意义 Ecological significance \\
\hline 膨压损失点 & - & 膨压是植物细胞因吸水体积膨胀而产生对细胞壁的压力。膨压损失点是发生初始质壁
\end{tabular}

Turgor loss point (TLP)

内部含水量

Internal water content $\left(W C_{\text {internal }}\right)$

共质体水

Symplastic water $(R s)$

质外体水

Apoplastic water $(R a)$

膨压损失点的相对含水量

Relative water content at turgor loss point $\left(R W C_{\mathrm{TLP}}\right)$

\section{膨压损失点的渗透势}

Water potential at turgor loss point ( $\left.\Psi_{\mathrm{TLP}}\right)$

\section{饱和渗透势}

Saturation water osmotic potential ( $\Psi$ sat $)$
分离时, 对细胞壁不产生压力, 膨压为 0 , 即膨压损失点。

Turgor pressure is the pressure that plant cells exert on the cell wall due to the expansion of water absorption volume. When the initial plasmolysis occurs, no pressure is generated on the cell wall, and the turgor pressure is zero, that is, the turgor loss point.

$\%$ 内部含水量为单位干质量生物体内的含水量。

The internal water content is the water content per unit dry weight in the organism.

$\%$ 细胞原生质体内即活的细胞内所包含的水分。

The water contained in cell protoplasts, that is, the water contained in living cells.

$\%$ 细胞原生质体外即活的细胞外所含的水分, 包括细胞壁、细胞间隙、导管、死亡细胞空 腔内等部分的水分。溶质含量不变时, $R a$ 越大, 组织渗透势越大, 吸水和保水能力越强, 植物抗旱性越强。

The water contained outside the protoplast that is outside the living cell, including the water in cell walls, intercellular spaces, ducts, and cavities of dead cells. When the solute content is constant, the bigger the apoplastic water, the larger the tissue penetration potential, the stronger the water absorption and retention capacity, and the stronger the drought resistance of the plant.

$\%$ 初始质壁分离时的相对含水量。 $R W C_{\mathrm{TL}}$ 越低, 植物组织忍耐脱水能力越强, 抗早性越 强。

$R W C_{\text {TLP }}$ refers to the relative water content of the initial mass wall separation. The lower the $R W C_{\mathrm{TL}}$, the stronger the ability of plant tissues to tolerate dehydration and the stronger the drought resistance.

$\mathrm{MPa}$ 质壁分离时的渗透势, 反映植物维持最低膨压的极限渗透势; $\Psi_{\mathrm{TL}}$ 越低, 植物维持膨压 能力越强, 干旱忍耐性越强。

$\Psi_{\text {TLP }}$ refers to the osmotic potential when the plasmodium is separated, reflecting the limit osmotic potential of plants to maintain the lowest turgor pressure. The lower the $\Psi_{\text {TLP }}$, the stronger the plant's ability to maintain turgor pressure and the stronger drought tolerance.

MPa 水分饱和时因细胞内溶质积累引起的水势; $\Psi$ sat越低, 细胞液浓度越高, 植物忍耐脱水 能力越强, 抗早能力越强。

$\Psi$ sat refers to the water potential caused by the accumulation of solutes in the cells when the sample are saturated with water. The lower the $\Psi$ sat, the higher the concentration of cell sap, the stronger the ability of plants to tolerate dehydration and the stronger the ability to resist drought.

引自Eriksson等(2017); Tyree和Hammel (1972); Yan等(2013); 李海涛和陈灵芝(1998).

Modified from Eriksson et al. (2018). Tyree \& Hammel (1972); Yan et al., (2013); Li \& Chen (1998).

\section{参考文献}

Esseen PA, Rönnqvist M, Gauslaa Y, Coxson DS (2017). Externally held water-A key factor for hair lichens in boreal forest canopies. Fungal Ecology, 30, 29-38.

Tyree MT, Hammel HT (1972). The measurement of the turgor pressure and the water relations of plants by the pressure-bomb technique. Journal of Experimental Botany, 23, 267-282.

Yan MJ, Yamamoto M, Yamanaka N, Yamamoto F, Liu GB, Du S (2013). A comparison of pressure-volume curves with and without rehydration pretreatment in eight woody species of the semiarid Loess Plateau. Acta Physiologiae Plantarum, 35, 1051-1060.

Li HT, Chen LZ (1998). The hydro-physiological characteristics of major plant species of the forest ecosystem in the warm temperate zone of Northern China. Acta Phytoecologica Sinica, 22, 202-213. [李海涛, 陈灵芝 (1998). 暖温带森林生态系统主要树种若 干水分参数的季节变化. 植物生态学报, 22, 202-213.] 
董琳琳, 普晓妍, 张璐璐, 宋亮, 鲁志云, 李苏 (2021). 亚热带森林附生地衣压力-体积曲线分析及其适用性. 植物生态学报, 45, 274-285. DOI: 10.17521/cjpe.2020.0344

Dong LL, Pu XY, Zhang LL, Song L, Lu ZY, Li S (2021). Pressure-volume curve analysis of epiphytic lichens and its applicability in subtropical forests. Chinese Journal of Plant Ecology, 45, 274-285. DOI: 10.17521/cjpe. 2020.0344

https://www.plant-ecology.com/CN/10.17521/cjpe.2020.0344

附录II 云南哀牢山亚热带森林15种附生地衣水势参数的相关性

Supplement II Correlations for water potential parameters across 15 epiphytic lichens in subtropical forests in the Ailao Mountains, Yunnan

\begin{tabular}{|c|c|c|c|c|c|c|}
\hline 参数 & 共质体水 & 质外体水 & 质壁分离时相对 & 膨压损失点的渗 & 饱和渗透势 & 内部含水量 \\
\hline \multirow[t]{2}{*}{ Parameter } & \multirow[t]{2}{*}{$R s$} & \multirow[t]{2}{*}{$R a$} & 含水量 & 透势 & \multirow[t]{2}{*}{$\Psi$ sat } & \multirow[t]{2}{*}{$W C_{\text {internal }}$} \\
\hline & & & $R W C_{\mathrm{TLP}}$ & $\Psi_{\mathrm{TLP}}$ & & \\
\hline 共质体水 $R s$ & - & 0.307 & -0.538 & 0.265 & 0.506 & 0.997 \\
\hline 质外体水 $R a$ & 0.007 & - & 0.077 & 0.476 & 0.350 & 0.324 \\
\hline \multicolumn{7}{|l|}{ 量 $R W C_{\mathrm{TLP}}$} \\
\hline 膨压损失点的渗透势 & 0.022 & $<0.0001$ & 0.325 & - & 0.807 & 0.273 \\
\hline \multicolumn{7}{|l|}{$\Psi_{\mathrm{TLP}}$} \\
\hline 饱和渗透势 $\Psi$ sat & $<0.0001$ & 0.002 & $<0.0001$ & $<0.0001$ & - & 0.513 \\
\hline 内部含水量 $W C_{\text {internal }}$ & $<0.0001$ & 0.005 & $<0.0001$ & 0.018 & $<0.0001$ & - \\
\hline
\end{tabular}

Ysat, saturation water osmotic potential; $\Psi_{\mathrm{TLP}}$, water potential at turgor loss point; $R a$, apoplastic water; $R s$, symplastic water; $R W C_{\mathrm{TLP}}$, relative water content at turgor loss point; $W C_{\text {internal, }}$ internal water content. 
董琳琳, 普晓妍, 张璐璐, 宋亮, 鲁志云, 李苏 (2021). 亚热带森林附生地衣压力-体积曲线分析及其适用性. 植物生态学报, 45, 274-285. DOI: 10.17521/cjpe.2020.0344

Dong LL, Pu XY, Zhang LL, Song L, Lu ZY, Li S (2021). Pressure-volume curve analysis of epiphytic lichens and its applicability in subtropical forests. Chinese Journal of Plant Ecology, 45, 274-285. DOI: 10.17521/cjpe. 2020.0344

https://www.plant-ecology.com/CN/10.17521/cjpe.2020.0344

\section{附录III 云南哀牢山亚热带森林附生地衣与其他研究中不同植物类群压力-容积曲线参数单样本 $t$ 检验(平均值土标准误)}

Supplement III Pressure-volume curve parameters of epiphytic lichens in subtropical forests in the Ailao Mountains in Yunnan and results of one sample $t$-test between liches and other plant growth forms (mean $\pm S E$ )

\begin{tabular}{|c|c|c|c|}
\hline \multirow[t]{2}{*}{ 植物类群 Plant growth form } & 质壁分离时相对含水量 & 膨压损失点的渗透势 & 饱和渗透势 \\
\hline & $R W C_{\mathrm{TLP}}$ & $\Psi_{\mathrm{TLP}}$ & $\Psi$ sat \\
\hline 附生地衣 Epiphytic lichen & $45.74 \pm 12.78$ & $-3.73 \pm 1.60$ & $-1.62 \pm 0.81$ \\
\hline 苔藓 Bryophyte & $65.20^{* * *}$ & $-3.13^{* *}$ & $-1.93^{* *}$ \\
\hline 草本 Herb & $33.23^{* * *}$ & $-2.41^{* * *}$ & -1.61 \\
\hline 乔木 Tree & $87.97^{* * *}$ & $-2.60^{* * *}$ & $-2.12^{* * *}$ \\
\hline
\end{tabular}

引自Song等(2015); He等(2007); Yan等(2013); Castro-Díez \& Navarro (2007).

$\Psi$ sat, saturation water osmotic potential; $\Psi_{\mathrm{TLP}}$, water potential at turgor loss point; $R W C_{\mathrm{TLP}}$, relative water content at turgor loss point. $* * *, p<0.001 ; * *, p<$ 0.01; *, $p<0.05$ 。 Modified from Song et al., (2015); He et al., (2007); Yan et al., (2013); Castro-Díez \& Navarro (2007).

\section{参考文献}

He XD, Cong PF, Gao YB, Lu JG, Wang HT, Xue PP, Zhang X (2007). Drought resistance of four grasses using pressure-volume curve. Frontiers of Biology in China, 2, 425-430.

Song L, Zhang YJ, Chen X, Li S, Lu HZ, Wu CS, Tan ZH, Liu WY, Shi XM (2015). Water relations and gas exchange of fan bryophytes and their adaptations to microhabitats in an Asian subtropical montane cloud forest. Journal of Plant Research, 128, 573-584.

Yan MJ, Yamamoto M, Yamanaka N, Yamamoto F, Liu GB, Du S (2013). A comparison of pressure-volume curves with and without rehydration pretreatment in eight woody species of the semiarid Loess Plateau. Acta Physiologiae Plantarum, 35, 1051-1060.

Castro-Díez P, Navarro J (2007). Water relations of seedlings of three Quercus species: variations across and within species grown in contrasting light and water regimes. Tree Physiology, 27, 1011-1018. 